This document is the Accepted Manuscript version of a Published Work that appeared in final form in Applied Materials and Interfaces copyright $\odot$ American Chemical Society after peer review and technical editing by publisher. To access the final edited and published work see Pautler, R., Kelly, E. Y., Huang, P.-J. J., Cao, J., Liu, B., \& Liu, J. (2013). Attaching DNA to Nanoceria: Regulating Oxidase Activity and Fluorescence Quenching. ACS Applied Materials \& Interfaces, 5(15), 6820-6825. https://doi.org/10.1021/am4018863

\title{
Attaching DNA to Nanoceria: Regulating Oxidase Activity and Fluorescence Quenching
}

\author{
Rachel Pautler, Erin Y. Kelly, Po-Jung Jimmy Huang, Jing Cao, Biwu Liu and Juewen Liu*
}

Department of Chemistry and Waterloo Institute for Nanotechnology, University of Waterloo, Waterloo, Ontario, Canada, N2L 3G1

E-mail: liujw@uwaterloo.ca

\begin{abstract}
Cerium oxide nanoparticles (nanoceria) have recently emerged as a nanozyme with oxidase activity. In this work we present a few important interfacial properties of nanoceria. First, the surface charge of nanoceria can be controlled not only by adjusting $\mathrm{pH}$ but also by adsorption of simple inorganic anions. Adsorption of phosphate and citrate gives negatively charged surface over a broad $\mathrm{pH}$ range. Second, nanoceria adsorbs DNA via the DNA phosphate backbone in a sequence-independent manner; DNA adsorption inhibits its oxidase activity. Other anionic polymers display much weaker inhibition effects. Adsorption of simple inorganic phosphate does not have the inhibition effect. Third, nanoceria is a quencher for many fluorophores. These discoveries provide an important understanding for further use of nanoceria in biosensor development, materials science and nanotechnology.
\end{abstract}

Keywords: cerium oxide, nanozymes, adsorption, surface charge, oxidase

Enzymes usually refer to protein-based biocatalysts with high activity and substrate specificity; they play crucial roles in life and are the central molecules in biochemistry, biotechnology and analytical 
chemistry. Recently, many inorganic nanoparticles have been reported to have enzyme-like activities (so-called nanozymes). ${ }^{1,2}$ An early example was reported by Manea et al; they used gold nanoparticles (AuNPs) to cleave phosphodiester bonds, mimicking the nuclease activity. ${ }^{3}$ Recently, AuNPs were employed to mimic glucose oxidase, where glucose was oxidized to produce hydrogen peroxide. ${ }^{4-6}$ Esterase activity was also achieved with $\beta$-cyclodextrin-modified AuNPs. ${ }^{7}$ In addition, iron oxide NPs have been found to have peroxidase-like activity. ${ }^{8,9}$ Cerium oxide nanoparticles (nanoceria) were reported to be a general oxidase that can oxidize many substrates; ${ }^{10}$ they also act as a dismutase and catalase mimic. ${ }^{11-13}$ Detailed mechanistic studies indicate that nanoceria might be converted to other species in the reaction process. ${ }^{14}$ Compared to protein enzymes, these nanoparticle-based catalysts are attractive since they are more stable under harsh conditions, costeffective to produce and do not suffer from denaturation. Nanoparticles have a high specific surface area, allowing the surface to be readily engineered to interact with various molecules. In contrast, it is more difficult to change the surface property of proteins without denaturing them or undergoing mutagenesis. Since catalytic reactions take place only at the particle surface, surface chemistry is important to further the research and to find new applications. Many nanoparticles can adsorb both

small molecules and polymers, ${ }^{15,16}$ where such adsorbed molecules might change the interaction between a nanozyme and its substrate. Therefore, it might be possible to regulate the catalytic activity of nanozymes through adsorption.

Among the various nanozymes, we are interested in nanoceria because of its high catalytic activity and excellent biocompatibility. Nanoceria has been extensively tested as an anti-oxidation agent and to stimulate the growth of stem cells. ${ }^{17-20}$ Previous studies have used it for designing colorimetric biosensors. ${ }^{21,22}$ Nanoceria has been reported to adsorb proteins based on electrostatic interactions. $^{23}$ 
In recent years, DNA has become a central molecule in bionanotechnology. Materials that can adsorb DNA are interesting for developing biosensors, analytical separation, and for gene delivery. ${ }^{24-30}$ A native B-form double-stranded (ds) DNA is a highly negatively charged rod that can interact with surfaces via electrostatic forces. On the other hand, for single-stranded (ss) DNA, many intermolecular forces can take place including aromatic stacking, metal coordination, hydrogen bonding, hydrophobic force and electrostatic force. While a lot of attention has been focused on metallic nanoparticles and carbon-based materials, ${ }^{15,16,25,26,31-33}$ oxides other than silica have been underexplored. In this work, we study adsorption of DNA by nanoceria, and show that adsorbed DNA can regulate its oxidase activity, presumably due to blocking substrate accessibility. Interestingly, nanoceria also has strong fluorescence quenching ability, providing further potential in biosensor development.

The oxidation of 3,3',5,5'-tetramethylbenzidine (TMB) by nanoceria is a well established reaction to generate a blue-colored product (Figure 1A). The hydrodynamic diameter of our nanoceria is $\sim 5-8 \mathrm{~nm}$ as measured by dynamic light scattering (Figure 1C) when dispersed either in dilute acetic acid or in water. The size distribution is, however, quite broad. Transmission electron microscopy (TEM) confirms that the actual particle size is indeed around $5 \mathrm{~nm}$, but some particles form small aggregates (Figure S1, Supporting Information). The particles do not have a welldefined shape, and therefore, the diameter of $5 \mathrm{~nm}$ is only an approximation. To adsorb DNA, the surface charge of nanoceria is important and the $\mathrm{Q}$-potential of nanoceria was measured as a function of $\mathrm{pH}$ in various buffers. When dispersed in water with just $10 \mathrm{mM} \mathrm{NaCl}$ but no buffer (red triangles, Figure 1D) or using acetate (black dots) as a buffer, we observed a similar trend that the particles are positively charged at low $\mathrm{pH}$ and negatively charged at high $\mathrm{pH}$, where the transition takes place at $\sim \mathrm{pH} 8$ for both samples. Therefore, nanoceria is likely to be protonated at low $\mathrm{pH}$. Large fluctuations in the measurement are observed at $\mathrm{pH} 7-8$, since there is no buffer in these samples (note that acetate loses its buffering power beyond $\mathrm{pH}$ 7). Interestingly, when either citrate or 
phosphate was used as buffer, the particles remained negatively charged from $\mathrm{pH} 3.5$ to $\mathrm{pH} 11.5$ (Figure 1D). We reason that citrate and phosphate ions must have adsorbed onto the particle surface to result in an inversion of surface charge at lower $\mathrm{pH}$. From the chemistry stand point, lanthanide ions such as cerium are hard Lewis acids and they should have high affinity with hard ligands such as phosphate and carboxyl groups. There are also reports of phosphate in affecting the redox property of nanoceria. ${ }^{34,35}$ It is interesting to compare acetate with citrate. While both have carboxyl groups, citrate appears to have stronger affinity due to the chelation effect. Nanoceria showed slight aggregation in phosphate and citrate buffer (average size below $50 \mathrm{~nm}$ ) but extensive aggregation in MES or by adding $\mathrm{NaCl}$ as measured by DLS (Figure S2). The higher stability in phosphate and citrate might be related to the negatively charged surface.
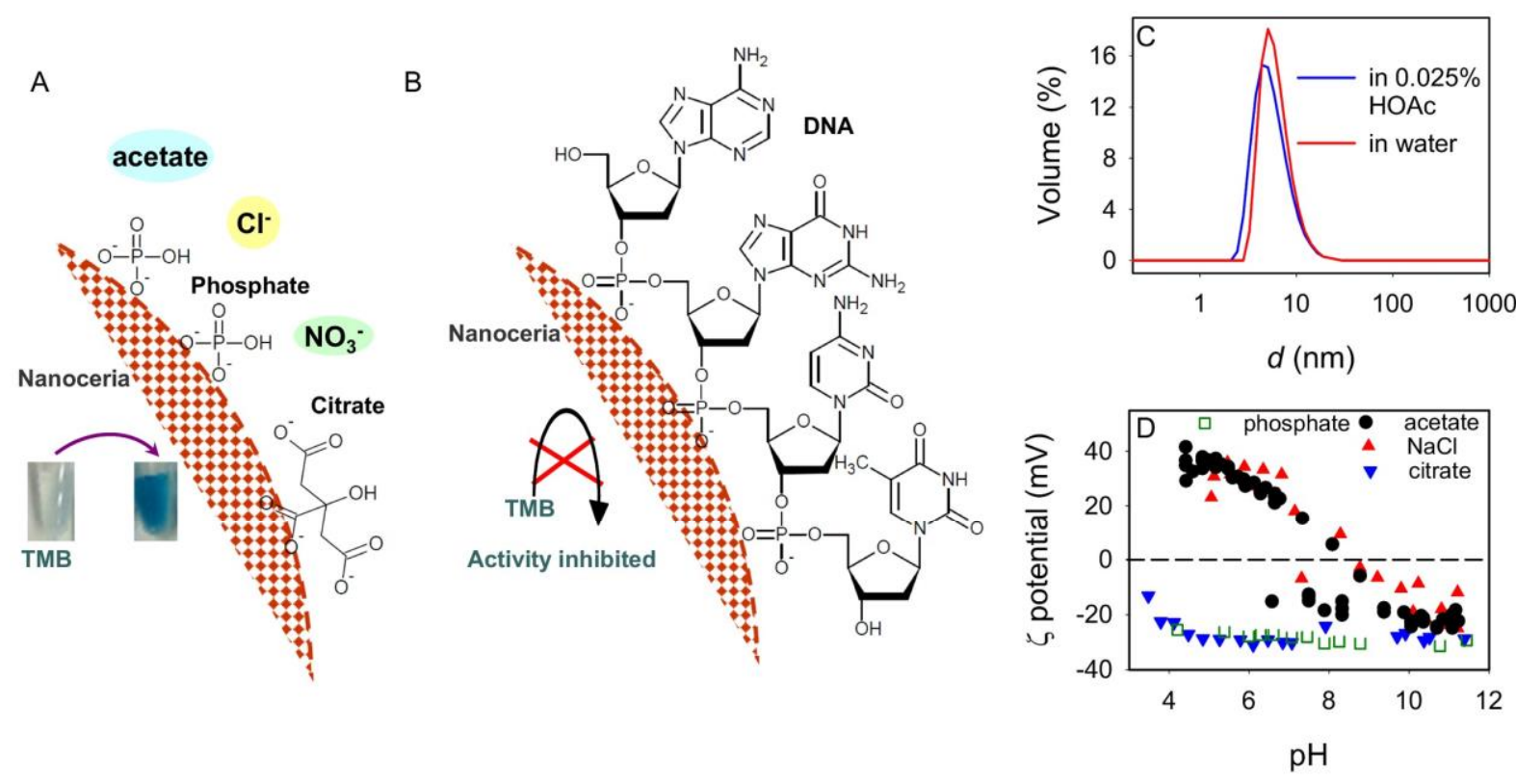

Figure 1. (A) Cartoon showing that nanoceria can tightly adsorb phosphate and citrate, resulting in negatively charged surface, but with low affinity with acetate, chloride and nitrate. Its oxidase activity is retained in all these buffers to convert TMB into a blue product. (B) Nanoceria adsorbs DNA via the phosphate backbone. The oxidase activity is inhibited upon DNA adsorption. (C) DLS spectra of nanoceria dispersed in an acidic buffer or in water. (D) D-potential of nanoceria as a function of $\mathrm{pH}$ in various buffer conditions (10 $\mathrm{mM}$ phosphate, citrate or acetate). The sample marked with $\mathrm{NaCl}(10 \mathrm{mM})$ does not contain any buffer. 
Based on the surface charge measurement, we reason that it might be possible to adsorb DNA based on both electrostatic attraction and specific binding, in particular considering that the backbone of DNA is phosphate. At the same time, release of DNA might be achieved by raising the $\mathrm{pH}$ or by adding competing salts such as phosphate or citrate. As an initial test, we mixed a fixed concentration of DNA1 (carboxyfluorescein (FAM)-labeled 10-nucleotide long) with various concentrations of nanoceria in water, where fully quenched fluorescence was observed at high particle concentrations (Figure 2A). This observation suggests that nanoceria not only adsorbs DNA but also strongly quenches fluorescence, providing a convenient analytical handle. Further studies indicate that nanoceria is a general quencher and can quench green, red and far red dyes labeled on DNA (Figure 2C). Since quenching occurs even at very low ratio between DNA and nanoceria (e.g. one nanoceria has maximally one DNA), it is unlikely that quenching is due to aggregation of fluorophore on the particle surface, but rather due to direct interaction with the particles. Since a broad range of emission wavelengths can be quenched and nanoceria does not have light absorption in the visible region (see Figure S3 for UV-vis spectrum), the mechanism of quenching should not be energy transfer. Instead, we propose that there might be electron transfer between excited fluorophores and nanoceria, which is a high band-gap semiconductor.

The mixture of nanoceria and DNA also showed aggregation as indicated by DLS (Figure S4), possibly due to that each DNA can bind more than one particle. Next we analyzed the samples using non-denaturing gel electrophoresis (Figure 2B). The numbers on each lane are the molar ratio between DNA and nanoceria, where the first lane on the left did not contain any nanoceria. In agreement with Figure 2A, we observed the free DNA band for the first three lanes, where DNA was in excess. After that, only smeared DNA bands were observed, suggesting that the DNA was gradually released from nanoceria under the applied electric field. Therefore the binding between DNA and nanoceria is reversible, which is expected for non-covalent interactions. Quantitative measurement of fluorescence intensity drop gives that each nanoceria adsorbs $\sim 10$ DNA1 molecules (10-nucleotide long) on each $5 \mathrm{~nm}$ nanoceria at the 15:1 ratio between DNA and nanoceria. The 
ultimate capacity is $~ 20$ DNA based on the Langmuir adsorption model. As will be explained later, the adsorption capacity is also a function of DNA length.
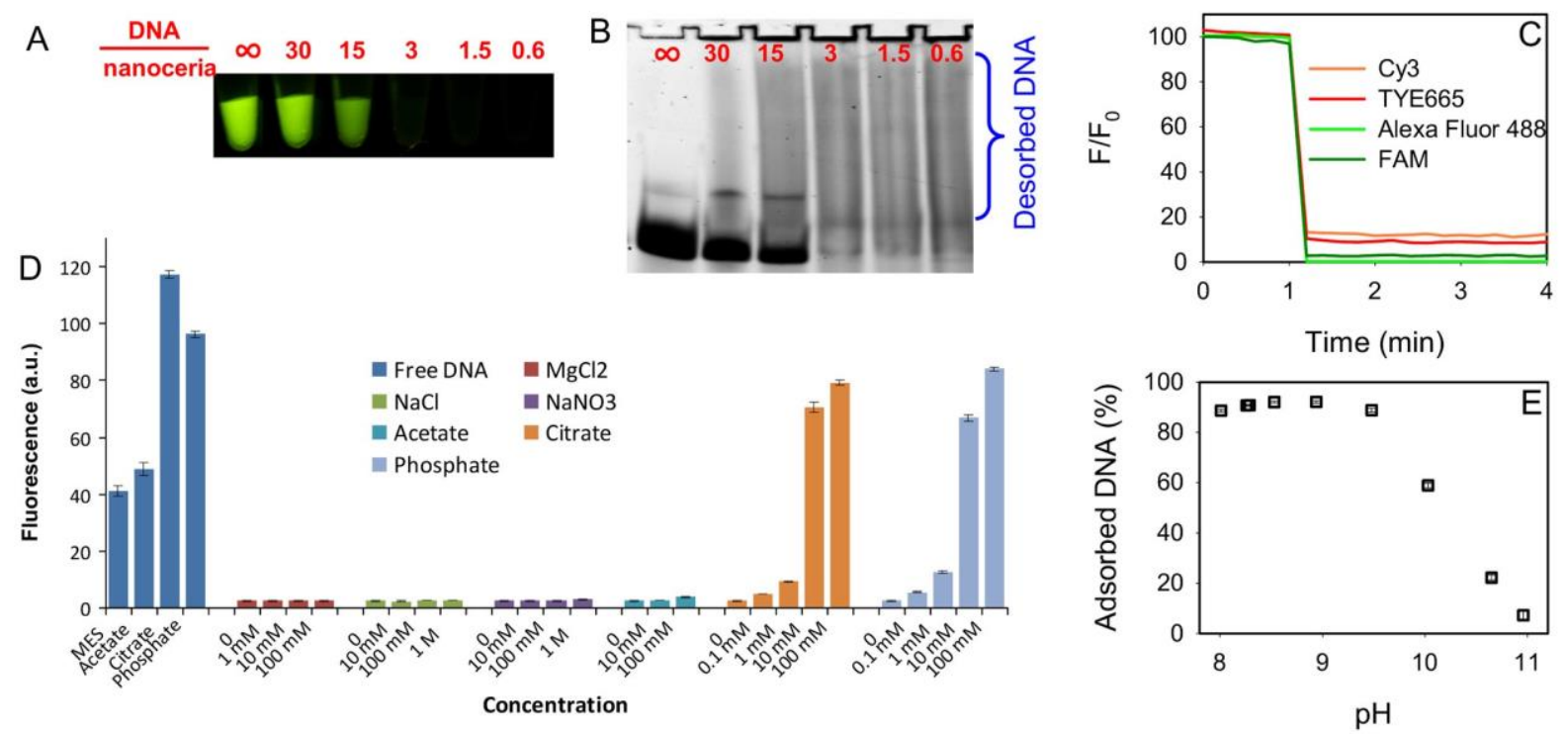

Figure 2. (A) Photograph of FAM-labeled DNA1 and nanoceria mixed at various ratios in water. (B) Non-denaturing polyacrylamide gel electrophoresis of the samples in (A), where the first lane on the left does not contain any nanoceria. (C) Quenching of various fluorophore-labeled DNA by nanoceria. (D) Fluorescence intensity of FAM-labeled DNA mixed with nanoceria in various buffers. The first bar on the left does not contain any nanoceria, while the rest of the samples contain an excess concentration of nanoceria in various buffers. All measurements were at pH 6. (E) Change of DNA adsorption capacity on nanoceria as a function of $\mathrm{pH}$.

Nanoceria becomes negatively charged at $\mathrm{pH}$ greater than $\sim 8$, where charge repulsion with DNA is expected. To test this, we next measured DNA adsorption as a function of pH (Figure 2E). Interestingly, DNA adsorption was completely inhibited only when $\mathrm{pH}$ was approaching 11, and more than 50\% DNA was adsorbed even at $\mathrm{pH} 10$. Therefore, in addition to electrostatic interaction, other attractive forces must also exist, such as specific binding through the DNA phosphate. Otherwise, DNA should be repelled beyond $\mathrm{pH}$ 8. This binding can be understood from the hard metal (cerium) and hard ligand (phosphate) theory. Direct phosphate oxygen coordination has also been suggested in other materials. ${ }^{36}$ To further understand DNA adsorption, we tested the effect of 
buffer and salt. The fluorescence of the free DNA was first measured as reference (Figure 2D, blue bars on the left). The amount of adsorbed DNA can be estimated based on fluorescence quenching. Up to $100 \mathrm{mM} \mathrm{MgCl}_{2}, 1 \mathrm{M} \mathrm{NaCl}, 1 \mathrm{M} \mathrm{NaNO}_{3}$ or $100 \mathrm{mM} \mathrm{NaOAc}$ had little effect on the adsorption of DNA, where close to complete DNA adsorption was observed. Since electrostatic interaction is likely to be screened in such high salt conditions, this experiment further confirms that the binding of DNA to nanoceria is not a pure electrostatic interaction. On the other hand, even $1 \mathrm{mM}$ citrate or phosphate started to show DNA desorption, while $10 \mathrm{mM}$ of these two salts resulted in significant DNA desorption. If the buffers were added prior to DNA addition, inhibition of DNA adsorption occurred with just $1 \mathrm{mM}$ phosphate or citrate (Figure S5, Supporting Information). This result is consistent with the previous $\square$-potential measurement that citrate and phosphate are adsorbed strongly by nanoceria to make the surface negatively charged and mask the cerium ions on the surface, blocking electrostatic and chemical interactions with DNA. The lack of fluorescence drop in citrate and phosphate buffer also serves as a control experiment, indicating that the fluorescence quenching by nanoceria is due to DNA adsorption instead of artifacts.

We further studied the effect of DNA sequence, where FAM-labeled 15-mer of poly-A, T, $\mathrm{C}$ and $\mathrm{G}$ all showed similar adsorption capacity. This also indicates that DNA adsorption does not occur through the bases but through the phosphate backbone (Figure 3A). For comparison, DNA adsorption by graphene and gold is strongly dependent on the base composition, since adsorption was made through the bases. ${ }^{16,37,38}$ Next, we tested the effect of DNA length and found that the adsorption capacity decreased as the length of DNA was increased, suggesting a DNA wrapping model of adsorption (Figure 3B). In particular, the adsorption capacity of $\mathrm{A}_{30}$ (e.g. homopolymer of thirty adenines) is roughly three times of that $A_{90}$, indicating that each nanoparticle adsorbs roughly the same number of nucleotides. The length-dependent DNA adsorption was also tested by gel electrophoresis (Figure S6, S7), where longer DNA was confirmed to adsorb more tightly and hydrogen bonding should not be important for DNA adsorption (Figure S8). The $\square$-potential of 
nanoceria was also followed by adding increasing concentrations of DNA and the inversion of surface charge from positive to negative was observed (Figure 3C), confirming that DNA was coating the particle surface.

Finally, the complex was subject to a heat induced desorption experiment (Figure 3D). As expected, free FAM-labeled DNA showed decreased fluorescence at higher temperature. When mixed with nanoceria, the initial fluorescence was low. FAM-A 15 started to desorb at greater than 70 पC while FAM-A90 desorbed at even higher temperature, also reflecting longer DNA adsorbing more tightly. We further compared the adsorption kinetics of ss- and ds-DNA, where ss-DNA showed faster adsorption with a greater extent of fluorescence quenching in a minute. Ds-DNA also showed significant fluorescence quenching over a longer period of time (Figure 3E), which is expected since DNA adsorption is based on the phosphate interaction. It is likely that the ds-DNA is more rigid and cannot wrap around nanoceria as effectively; some of the fluorophores are not completely quenched. Next we employed FAM-T 15 as a probe and respectively mixed it with nonlabeled $\mathrm{A}_{15}, \mathrm{C}_{15}$ and $\mathrm{T}_{15}$. Without nanoceria, the free DNA samples showed similarly high fluorescence (black bars, Figure $3 F$ ). With the addition of nanoceria, only the $A_{15}$ sample showed high fluorescence (gray bars), which is consistent with the result in Figure 3E. Therefore, nanoceria has selectivity for ss-DNA over ds-DNA. 

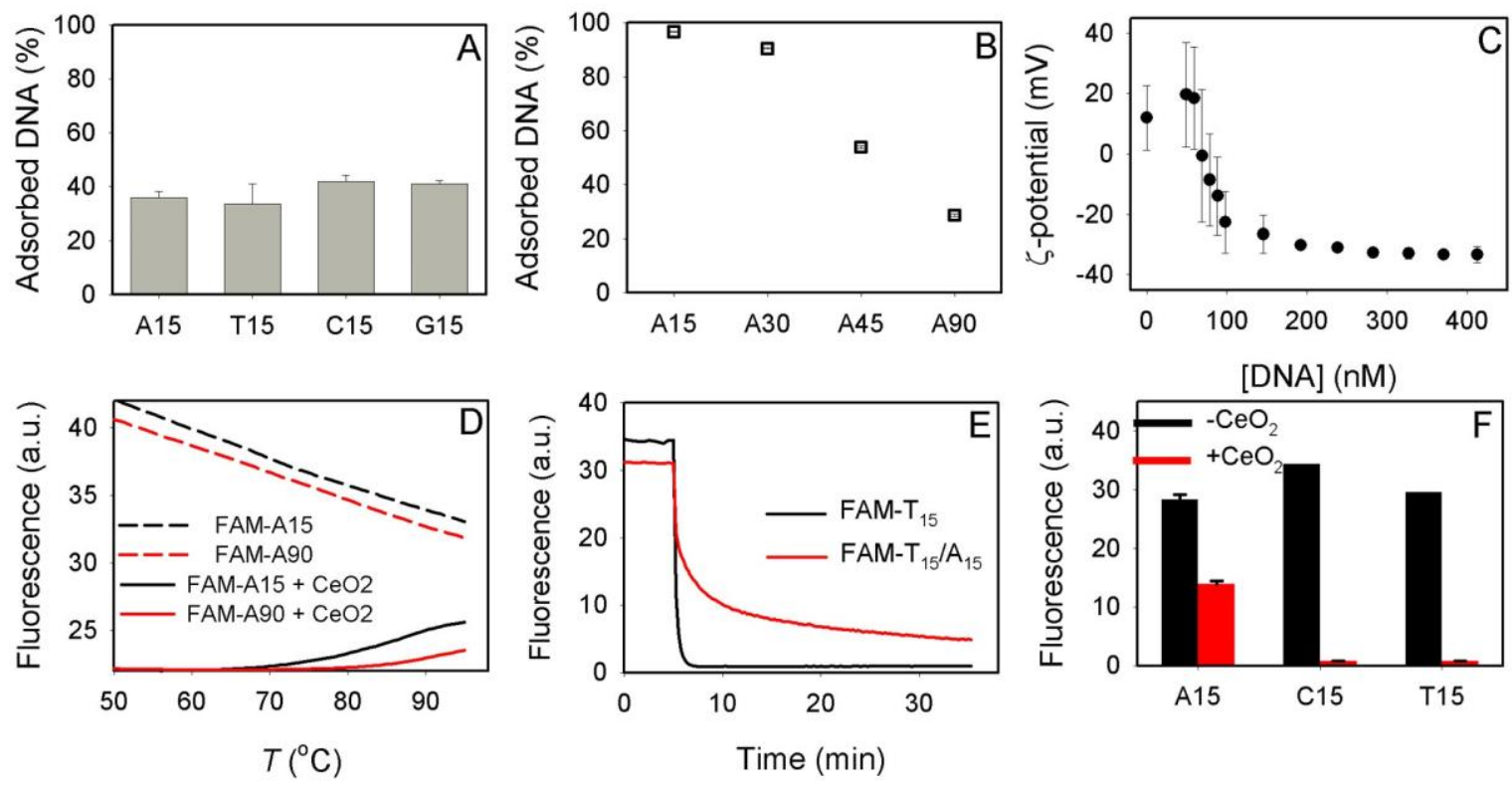

Figure 3. Adsorption of DNA by nanoceria as a function of DNA sequence (A) and DNA length (B). (C) DNA adsorption inverts the D-potential of nanoceria. (D) Thermal desorption of DNA from nanoceria. (E) DNA adsorption kinetics measured by fluorescence quenching; ds-DNA adsorbed more slowly compared to ss-DNA. (F) Fluorescence-based measurement of ss- and ds-DNA adsorption, where FAM- $\mathrm{T}_{15}$ was used for all the samples. Only $\mathrm{A}_{15}$ resulted in high fluorescence with nanoceria, suggesting less effective adsorption of ds-DNA.

After understanding DNA adsorption by nanoceria, we next tested whether the adsorbed DNA could inhibit its oxidase activity. First a visual test was performed by comparing the color of TMB mixed with nanoceria in the absence or presence of 5 पM DNA (Figure 4A). The sample without DNA1 turned blue as expected but the sample with DNA remained colorless, suggesting the adsorbed DNA inhibited the oxidase activity. We then carefully monitored the absorbance at $650 \mathrm{~nm}$ with various DNA concentrations, where even $100 \mathrm{nM}$ DNA was able to show a significant difference (Figure 4B). Since DNA1 contains a fluorophore label, we also monitored the fluorescence change in this process. Initially the fluorescence was close to zero since most of the DNA molecules were adsorbed by nanoceria. The generation of fluorescence signal correlates well with the inhibited color change, confirming the role of DNA in this inhibition reaction. 

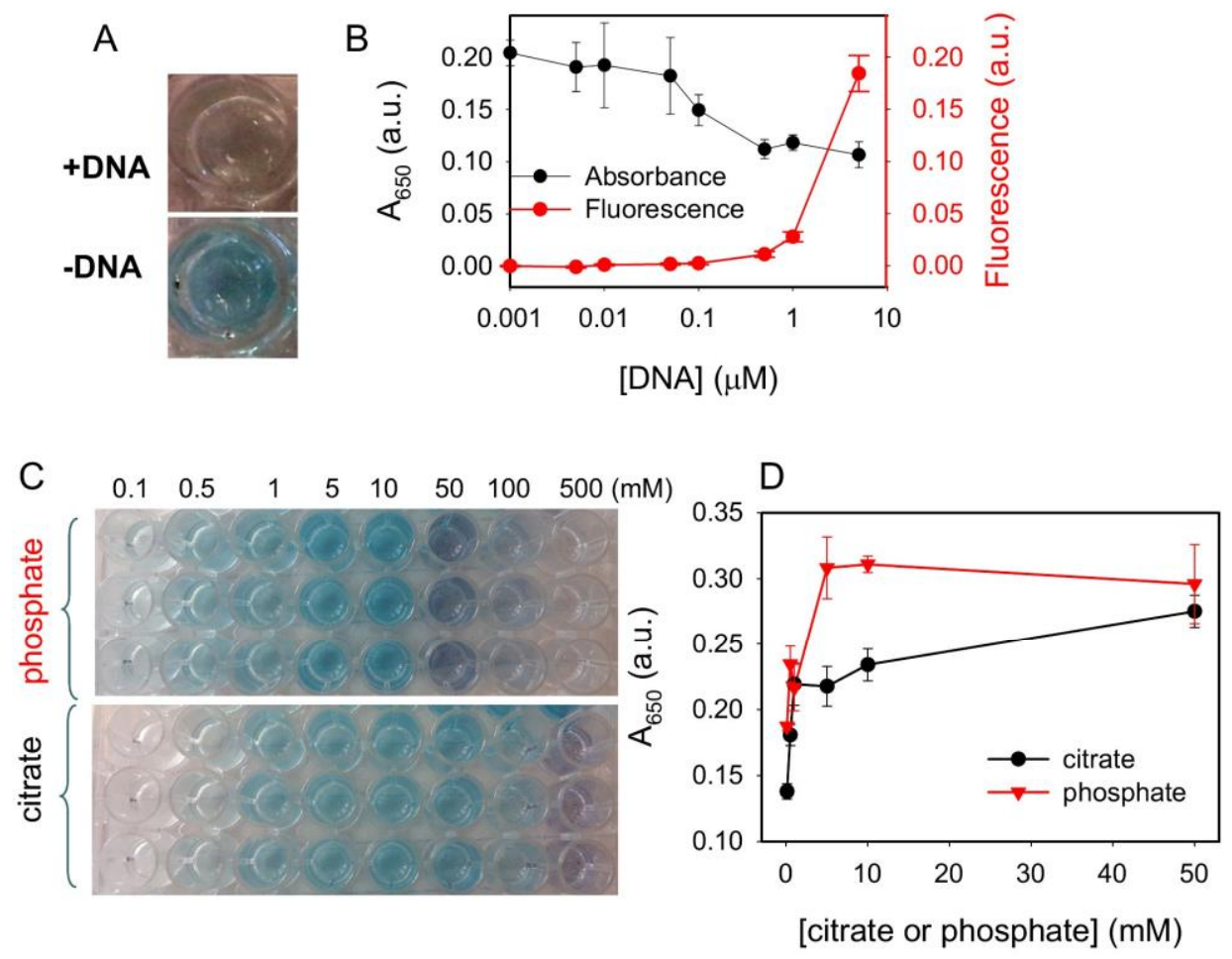

Figure 4. (A) Color of TMB sample mixed with nanoceria in the presence and absence of $5 \mathrm{DM}$ DNA. (B) Quantification of color by UV-vis spectrophotometer and the change of DNA fluorescence in this mixture. The FAM-labeled DNA1 was dissolved in $10 \mathrm{mM}$ acetate buffer, $\mathrm{pH}$ 4. The nanoceria concentration was $0.01 \%$ or $430 \mathrm{nM}$. (C) Color of TMB samples mixed with nanoceria in increasing concentrations of phosphate or citrate buffers ( $\mathrm{pH} 4)$. Deep blue colors at high buffer concentrations are due to precipitation. (D) Quantification of oxidation of the samples in (C) by monitoring absorbance at $650 \mathrm{~nm}$.

There are a few possible mechanisms for this inhibition to take place, such as binding of the surface cerium by the phosphate (e.g. chemical effect) or by the steric hindrance of DNA to inhibit substrate accessibility (e.g. physical effect). To further understand the mechanism, we carried out the reaction in increasing concentrations of citrate and phosphate buffers $(\mathrm{pH} 4)$, which are strong ligands for nanoceria. We chose $\mathrm{pH} 4$ to maximize the activity of nanoceria. ${ }^{10}$ Note that at low buffer concentrations, the $\mathrm{pH}$ might be close to neutral (e.g. $\mathrm{pH} \sim 6.0$ without buffer) and nanoceria might not have the optimal activity. For both buffers we observed an initial increase of blue color intensity as the buffer concentration was raised (Figure 4C), which is explained by the change of 
$\mathrm{pH}$ from neutral to 4 in this process. The absorbance change at $650 \mathrm{~nm}$ is plotted in Figure 4D to reflect the trend, where neither buffer caused inhibition. Note that $1 \mathrm{mM}$ phosphate or citrate can cover the nanoceria surface based on our DNA adsorption studies (Figure S5). At high buffer concentrations (>50 $\mathrm{mM}$ for phosphate and $500 \mathrm{mM}$ for citrate) deep blue precipitants were formed, causing artifacts in absorbance reading and these data points were not included for our discussion. Extensive aggregation with $500 \mathrm{mM}$ phosphate made the color nearly invisible. Nevertheless, the formation of blue color still indicates the oxidation reaction. Therefore, capping the nanoceria surface with small molecule anions does not inhibit its activity and DNA induced inhibition is likely due to the steric effect based on our data. Previous work has shown that the superoxide dismutase activity of nanoceria is inhibited by simple inorganic phosphate ions. ${ }^{34}$ However, its oxidase activity is not significantly affected as shown in the current study. Only when DNA with poly-phosphate backbone is used, its oxidase activity was inhibited.

Next, we tested a number of neutral and anionic polymers at $\mathrm{pH} 4$ to understand the specificity of using DNA as an inhibitor. As shown in Figure 5, only polystyrene sulfonate (PSS) and polyvinyl sulfate (PVS) showed dose-dependent inhibition, where close to complete inhibition was achieved with $2 \%$ PSS. When mixed with all the other polymers (e.g. polyacrylic acid (PAA), polyethylene glycol (PEG)), the nanoceria activity was not affected. Note that complete inhibition was achieved with just 5 पM DNA (i.e. $~ 0.004 \%$ ). Therefore, DNA is a much stronger inhibitor compared to all the tested polymers. Therefore, we reason that DNA inhibition of activity is due to a combination of its tight binding from the phosphate backbone and the steric repulsion between DNA and TMB. 

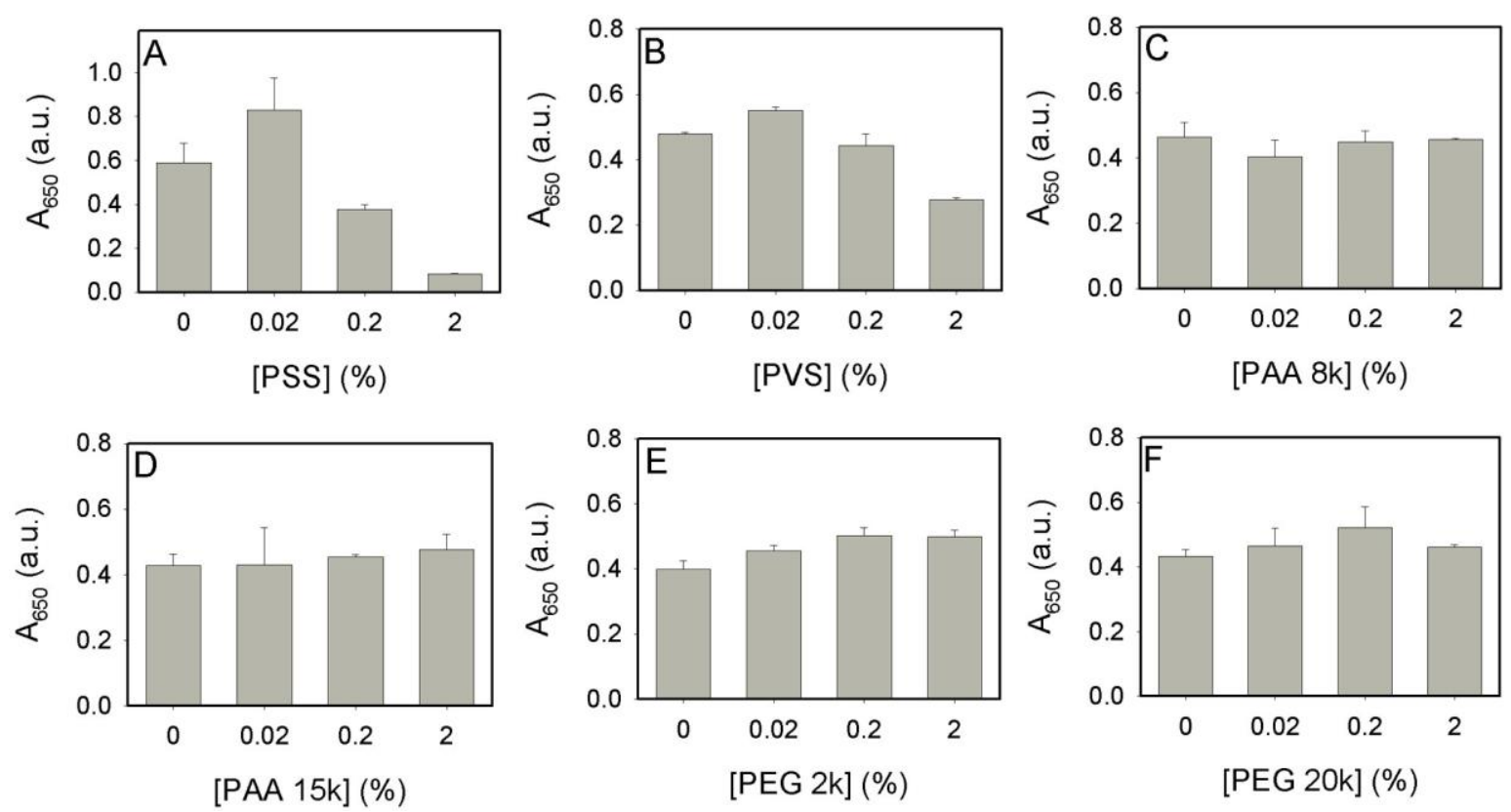

Figure 5. Absorbance of converted TMB by nanoceria in the presence of various polymers. The reaction pH was 4.0 controlled by $20 \mathrm{mM}$ citrate buffer. Only PSS shows strong inhibition at high concentration.

In summary, we reported the first study of DNA adsorption by nanoceria and revealed a number of interesting surface chemistry properties of nanoceria, allowing modulation of its catalytic activity. First, the surface charge of nanoceria can be controlled not only by changing pH but also by adsorbing small molecule anions, where citrate and phosphate can invert its charge from positive to negative. Second, DNA is effectively adsorbed by nanoceria independent to its base composition but longer DNA is adsorbed more tightly. In addition, ss-DNA is adsorbed more effectively than dsDNA as reflected by fluorescence quenching. DNA adsorption is made possible not only by electrostatic interaction but also through its phosphate backbone binding to cerium through Lewis acid-base interaction. Third, nanoceria is a strong and general fluorescence quencher. Fourth, DNA adsorption blocks the surface accessibility of substrate molecules, inhibiting the oxidase activity of nanoceria. Taken together, we believe this study will further stimulate the application of nanoceria in bioanalytical chemistry and nanotechnology. 
Supporting Information. The experimental details, TEM, additional DLS spectra, and additional DNA adsorption and gel electrophoresis data. This material is available free of charge via the Internet at http://pubs.acs.org.

Acknowledgements. Funding for this work is from the University of Waterloo, the Canadian Foundation for Innovation, and Natural Sciences and Engineering Research Council of Canada (NSERC). J. Liu receives Early Researcher Award from the Ontario Ministry of Research and Innovation.

\section{References}

(1) Kotov, N. A. Science 2010, 330, 188-189.

(2) Brown, C. J.; Bergman, R. G.; Raymond, K. N. J. Am. Chem. Soc. 2009, 131, 17530-17531.

(3) Manea, F.; Houillon, F. B.; Pasquato, L.; Scrimin, P. Angew. Chem., Int. Ed. 2004, 43, 6165-6169.

(4) Comotti, M.; Della Pina, C.; Matarrese, R.; Rossi, M. Angew. Chem., Int. Ed. 2004, 43, 5812-5815.

(5) Zheng, X.; Liu, Q.; Jing, C.; Li, Y.; Li, D.; Luo, W.; Wen, Y.; He, Y.; Huang, Q.; Long, Y.T.; Fan, C. Angew. Chem., Int. Ed. 2011, 50, 11994-11998.

(6) Luo, W.; Zhu, C.; Su, S.; Li, D.; He, Y.; Huang, Q.; Fan, C. ACS Nano 2010, 4, 7451-7458.

(7) Li, X.; Qi, Z.; Liang, K.; Bai, X.; Xu, J.; Liu, J.; Shen, J. Catal. Lett. 2008, 124, 413-417.

(8) Gao, L.; Zhuang, J.; Nie, L.; Zhang, J.; Zhang, Y.; Gu, N.; Wang, T.; Feng, J.; Yang, D.; Perrett, S.; Yan, X. Nat Nano 2007, 2, 577-583.

(9) Li, X.; Wen, F.; Creran, B.; Jeong, Y.; Zhang, X.; Rotello, V. M. Small 2012, 8, 3589-3592.

(10) Asati, A.; Santra, S.; Kaittanis, C.; Nath, S.; Perez, J. M. Angew. Chem., Int. Ed. 2009, 48, 2308-2312.

(11) Chen, J.; Patil, S.; Seal, S.; McGinnis, J. F. Nat Nano 2006, 1, 142-150. 
(12) Pirmohamed, T.; Dowding, J. M.; Singh, S.; Wasserman, B.; Heckert, E.; Karakoti, A. S.;

King, J. E. S.; Seal, S.; Self, W. T. Chem. Comm. 2010, 46, 2736-2738.

(13) Korsvik, C.; Patil, S.; Seal, S.; Self, W. T. Chem. Comm. 2007, 0, 1056-1058.

(14) Peng, Y.; Chen, X.; Yi, G.; Gao, Z. Chem. Comm. 2011, 47, 2916-2918.

(15) Wang, H.; Yang, R. H.; Yang, L.; Tan, W. H. ACS Nano 2009, 3, 2451-2460.

(16) Liu, J. Phys. Chem. Chem. Phys. 2012, 14, 10485-10496.

(17) Menchón, C.; Martín, R.; Apostolova, N.; Victor, V. M.; Álvaro, M.; Herance, J. R.; García, H. Small 2012, 8, 1895-1903.

(18) Mandoli, C.; Pagliari, F.; Pagliari, S.; Forte, G.; Di Nardo, P.; Licoccia, S.; Traversa, E. Adv. Funct. Mater. 2010, 20, 1617-1624.

(19) Karakoti, A. S.; Singh, S.; Kumar, A.; Malinska, M.; Kuchibhatla, S. V. N. T.; Wozniak, K.; Self, W. T.; Seal, S. J. Am. Chem. Soc. 2009, 131, 14144-14145.

(20) Celardo, I.; Pedersen, J. Z.; Traversa, E.; Ghibelli, L. Nanoscale 2011, 3, 1411-1420.

(21) Ornatska, M.; Sharpe, E.; Andreescu, D.; Andreescu, S. Anal. Chem. 2011, 83, 4273-4280.

(22) Sharpe, E.; Frasco, T.; Andreescu, D.; Andreescu, S. Analyst 2013, 138, 249-262.

(23) Patil, S.; Sandberg, A.; Heckert, E.; Self, W.; Seal, S. Biomaterials 2007, 28, 4600-4607.

(24) Yang, R. H.; Jin, J. Y.; Chen, Y.; Shao, N.; Kang, H. Z.; Xiao, Z.; Tang, Z. W.; Wu, Y. R.; Zhu, Z.; Tan, W. H. J. Am. Chem. Soc. 2008, 130, 8351-8358.

(25) Lu, C. H.; Yang, H. H.; Zhu, C. L.; Chen, X.; Chen, G. N. Angew. Chem. Int. Ed. 2009, 48, 4785-4787.

(26) He, S. J.; Song, B.; Li, D.; Zhu, C. F.; Qi, W. P.; Wen, Y. Q.; Wang, L. H.; Song, S. P.; Fang, H. P.; Fan, C. H. Adv. Funct. Mater. 2010, 20, 453-459.

(27) Li, H.; Rothberg, L. J. J. Am. Chem. Soc. 2004, 126, 10958-10961.

(28) Zhang, X.; Liu, B.; Dave, N.; Servos, M. R.; Liu, J. Langmuir 2012, 28, 17053-17060.

(29) Pei, H.; Li, F.; Wan, Y.; Wei, M.; Liu, H.; Su, Y.; Chen, N.; Huang, Q.; Fan, C. J. Am. 
Chem. Soc. 2012, 134, 11876-11879.

(30) Saha, K.; Agasti, S. S.; Kim, C.; Li, X.; Rotello, V. M. Chem. Rev. 2012, 2739-2779.

(31) Rosi, N. L.; Mirkin, C. A. Chem. Rev. 2005, 105, 1547-1562.

(32) Zhao, W.; Brook, M. A.; Li, Y. ChemBioChem 2008, 9, 2363-2371.

(33) Li, F.; Pei, H.; Wang, L.; Lu, J.; Gao, J.; Jiang, B.; Zhao, X.; Fan, C. Adv. Funct. Mater. 2013, 10.1002/adfm.201203816.

(34) Singh, S.; Dosani, T.; Karakoti, A. S.; Kumar, A.; Seal, S.; Self, W. T. Biomaterials 2011, $32,6745-6753$.

(35) Xue, Y.; Zhai, Y. W.; Zhou, K. B.; Wang, L.; Tan, H. N.; Luan, Q. F.; Yao, X. Chem. Eur. J. 2012, 18, 11115-11122.

(36) Liu, H. J. Phys. Chem. C 2009, 113, 3116-3119.

(37) Herne, T. M.; Tarlov, M. J. J. Am. Chem. Soc. 1997, 119, 8916-8920.

(38) Varghese, N.; Mogera, U.; Govindaraj, A.; Das, A.; Maiti, P. K.; Sood, A. K.; Rao, C. N. R. ChemPhysChem 2009, 10, 206-210. 